Sharif University of Technology
Scientia Iranica
SCIENTIA
IRANICA

\title{
Experimental and numerical study on the effect of aluminum foil wrapping on penetration resistance of ceramic tiles
}

\author{
H. Mazaheri ${ }^{a, *}$, R. Naghdabadi $i^{\mathrm{b}, \mathrm{c}}$ and J. Arghavani ${ }^{\mathrm{b}}$ \\ a. Department of Mechanical Engineering, Bu-Ali Sina University, Hamedan, Iran. \\ b. Department of Mechanical Engineering, Sharif University of Technology, Tehran, Iran. \\ c. Institute for Nano-Science and Technology, Sharif University of Technology, Tehran, Iran. \\ Received 25 November 2015; received in revised form 23 April 2016; accepted 4 July 2016
}

\author{
KEYWORDS \\ Penetration test; \\ Wrapped ceramic tile; \\ Aluminum foil; \\ Ballistic limit velocity; \\ Energy absorption.
}

\begin{abstract}
In this work, energy absorption of ceramic tiles wrapped by aluminum foil on its impact face is experimentally and numerically studied. Penetration tests as well as numerical simulations are employed to obtain Ballistic Limit Velocity (BLV) of the tiles. Experimental and numerical results yield BLV of bare tiles as $145 \pm 2$ and $141.5 \mathrm{~m} / \mathrm{s}$, respectively. For the wrapped tiles, these values are increased to $168 \pm 2$ and $162 \mathrm{~m} / \mathrm{s}$, respectively. Therefore, $13 \%$ increase in BLV of the ceramic tiles is obtained by just $2.4 \%$ increase in its weight. Moreover, it is shown that energy absorption of the wrapped tiles is at least $11 \%$ greater than that of the bare ones. Based on the results, the increase in BLV and energy absorption is due to the increase in the fracture conoid angle which postpones crack propagation to the back plate.

(C) 2017 Sharif University of Technology. All rights reserved.
\end{abstract}

\section{Introduction}

Besides ballistic projectiles, efficient and lightweight armors, such as ceramic armors, have been developed for long. Various ceramic tiles, such as alumina $\left(\mathrm{Al}_{2} \mathrm{O}_{3}\right)$, $\mathrm{SiC}, \mathrm{AlN}, \mathrm{Si}_{3} \mathrm{~N}_{4}$, and $\mathrm{TiB}_{2}$, are suggested for use in armors [1], among them alumina tiles are widely used, thanks to the low cost and their natural availability [2]. Since the ceramic tiles are brittle, they are weak in tension loads which occur in projectile impact. Thus, a metal or composite back-plate is used to strengthen ceramic tiles in tension and delay crack initiation as seen in ceramic armors [3-5]. As a result, penetration in the ceramic armors has attracted a great deal of interest in the literature. Analytical studies have been conducted for identifying optimized structure of these

*. Corresponding author. Tel.: +98-81-38381601-10;

Fax: +98-81-38380633

E-mail address: h.mazaheri@basu.ac.ir. (H. Mazaheri) armors which have maximum Ballistic Limit Velocity (BLV) [6-10]. Although analytic models are useful for analysis and optimization, to achieve precise results, numerical and experimental analyses are carried out in different aspects, such as optimization of adhesive layer thickness [11-13], thickness of the ceramic tile, and back plate [14-18]. Also, experimental studies on compactness of the ceramic tiles [19], their size [20], and using dual-phase back plates [21] are reported in the literature.

Due to the important role of the alumina ceramic tiles in the ceramic armors, a part of the research is devoted to penetration study of the alumina tiles [3,2228]. The effect of composition of the alumina ceramic tiles was investigated by Zhang and Li [27]. Moreover, confinement of the ceramic tiles was studied in the literature [29-35]. Confining the ceramic tiles delays the arrival of the tensile wave to the back face of the tiles and increases its energy absorption. Also, the effect of the confinement as well as back plate support 
and their effect on the damage mechanisms in ceramic tiles were illustrated [33-35]. Moreover, application of the ceramic tiles to new hybrid armors was studied [36].

Another approach to improve energy absorption of the ceramic tiles is wrapping the impact face of the ceramic tiles $[1,37]$. Sarva et al. studied the effect of the thin membrane wrapping on the ballistic performance and failure of the armor grade $\mathrm{Al}_{2} \mathrm{O}_{3}$ and $\mathrm{SiC}$ tiles at $900 \mathrm{~m} / \mathrm{s}$ [1]. They demonstrated that using an appropriate membrane enhances the ballistic performance of the ceramic tiles considerably. Moreover, wrapping the ceramic tiles by a polymer restraint was studied at $820 \mathrm{~m} / \mathrm{s}$ [37], and similar results were reported. It is worthwhile to mention that the formation of the pulverized ceramic particles at high velocity range and their collision with the projectile front result in projectile abrasion and energy absorption in the first stages of penetration. Normally, a part of the pulverized ceramic particles is dispersed and does not collide with the projectiles. Wrapping the ceramic tiles forces some of the dispersed pulverized ceramic particles to collide with the projectile, which results in more projectile abrasion and energy absorption at high velocity range [1].

In this paper, motivated from Sarva et al. [1] and Reddy et al. [37], the effect of the aluminum foil wrapping on the projectile penetration in the alumina ceramic tiles is experimentally and numerically investigated for medium velocity range. Moreover, the effect of the aluminum foil wrapping on BLV and energy absorption of the ceramic tiles is studied. It is worth mentioning that the failure mechanism of the ceramic tiles and the projectile at high velocity range is different from the medium one illustrated in this work.

To this end, a number of experiments are carried out on both wrapped and bare tiles. Experimental setup, specimen preparation, and experiments details are presented in Section 2. Numerical simulations of the experiments are presented in Section 3. The material parameters are identified in Section 3.1 and used in Section 3.2, where numerical simulation of the penetration tests is performed. The results of the experiments and simulations are discussed in Section 4 in which BLV of the ceramic tiles in both wrapped and bare cases is obtained and compared. Finally, in Section 5, we present a summary and draw conclusions.

\section{Penetration tests}

Penetration tests were employed to study the effect of the aluminum foil wrapping on the impact resistance and energy absorption of the ceramic tiles. Experimental setup and the specimen preparation are first explained. Then, the experiments' details are reported, and Ballistic Limit Velocity (BLV) of the ceramic tiles is calculated in both cases as follows.

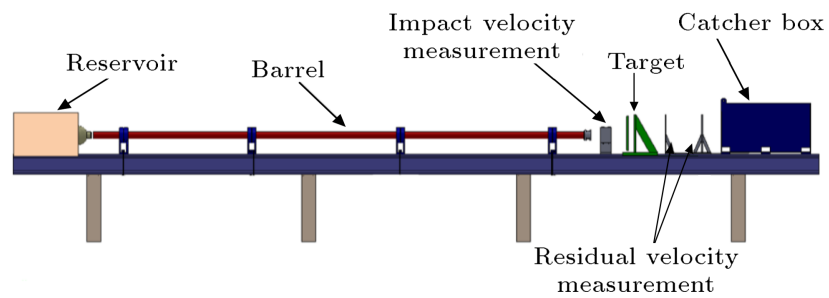

Figure 1. Schematic draw of the penetration test apparatus with accessories.

\subsection{Experimental setup}

As illustrated in Figure 1, the penetration tests are performed by the use of a nitrogen gas-gun. The length and diameter of the gas-gun barrel are $2.75 \mathrm{~m}$ and $20 \mathrm{~mm}$, respectively. Impact velocity of the projectile is measured by an optical device with accuracy of $\pm 2 \mathrm{~m} / \mathrm{s}$. In this work, the cylindrical projectiles are employed for penetration tests whose diameter and height are $7.62 \mathrm{~mm}$ and $22.80 \mathrm{~mm}$, respectively. The projectiles are made of 4340 steel and weight 8.1 grams. Due to the difference in the projectile diameter and inner diameter of the barrel, a PTFE sabot is employed to carry the projectile inside the barrel and prevent the barrel wear.

In this work, penetration tests are performed for both the wrapped and the bare tiles made of $99.5 \%$ alumina. The tiles are square-shaped with the side length of $50 \mathrm{~mm}$ and thickness of $10 \mathrm{~mm}$. An aluminum foil with thickness of $100 \mu \mathrm{m}$ is used to wrap the ceramic tiles on its impact and lateral faces, as shown in Figure 2. It is worthwhile to mention that the back face of the tile is free, and only the impact and lateral faces are wrapped. Also, methyl alpha cyanoacrylate adhesive with a very negligible thickness and mass is employed to attach the foil to the tiles.

\subsection{Experimental results}

Penetration tests are performed at various velocities for both cases, and the results are reported in Table 1.

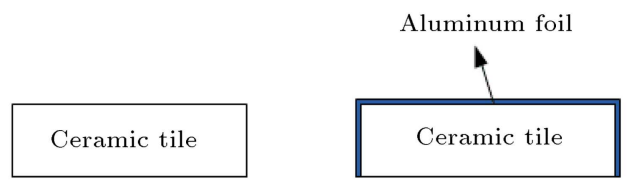

(a)

(b)

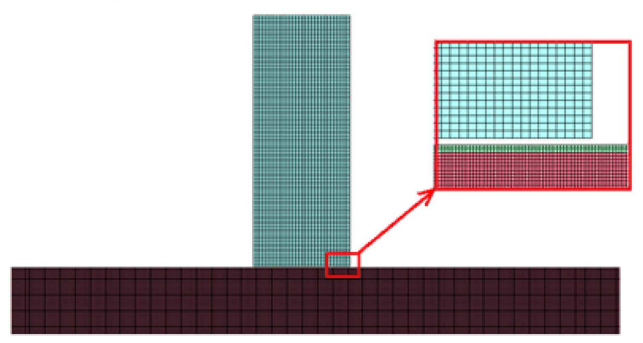

(c)

Figure 2. Schematics of (a) the bare and (b) the wrapped tiles for the penetration test. (c) The constructed numerical model. 
Table 1. Experimental results of penetration test on both wrapped and bare ceramic tiles.

\begin{tabular}{clccccc}
\hline $\begin{array}{c}\text { Test } \\
\text { no. }\end{array}$ & Condition & $\begin{array}{c}\text { Impact } \\
\text { velocity } \\
\mathbf{( m / s )}\end{array}$ & Perforation & $\begin{array}{c}\text { Projectile } \\
\text { final length } \\
\mathbf{( m m})\end{array}$ & $\begin{array}{c}\text { Projectile } \\
\text { kinetic energy } \\
\text { change }(\mathbf{J})\end{array}$ & $\begin{array}{c}\text { Projectile } \\
\text { absorbed } \\
\text { energy }(\mathbf{J})\end{array}$ \\
\hline 1 & Bare & $140 \pm 2$ & No & 22.36 & 79.4 & 25.3 \\
2 & Bare & $150 \pm 2$ & Yes & 22.29 & 91.1 & 29.0 \\
3 & Bare & $180 \pm 2$ & Yes & 21.93 & 131.2 & 52.8 \\
4 & Wrapped & $162 \pm 2$ & No & 22.29 & 106.3 & 29.0 \\
5 & Wrapped & $164 \pm 2$ & No & 22.24 & 114.3 & 31.5 \\
6 & Wrapped & $172 \pm 2$ & Yes & 22.20 & 119.8 & 35.3 \\
\hline
\end{tabular}

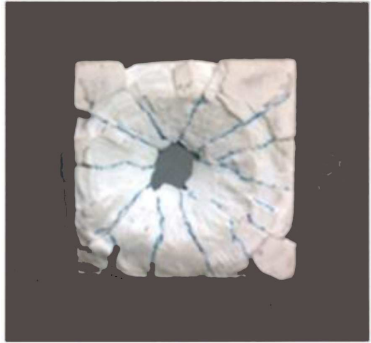

(a)

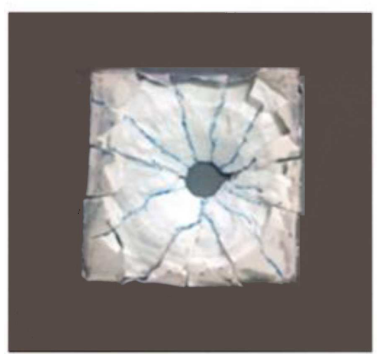

(c)

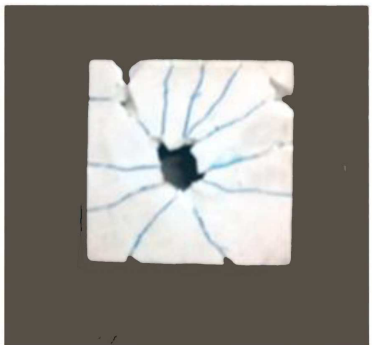

(b)

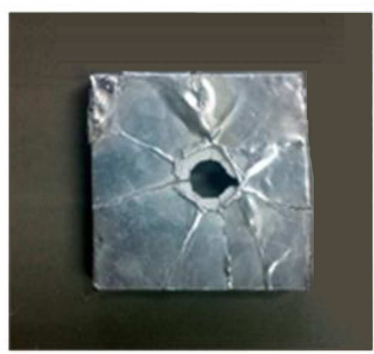

(d)
Figure 3. (a) Back and (b) impact face of a bare ceramic tile after impact at $150 \mathrm{~m} / \mathrm{s}$. (c) Back and (d) impact face of a wrapped ceramic tile after impact at $162 \mathrm{~m} / \mathrm{s}$.

The tiles are supported by a thick steel plate with a $45 \mathrm{~mm}$ circular hole to allow projectile perforation. Assembling the fractured tiles, formation of the fracture conoid after penetration test is depicted in Figure 3, in which two samples of wrapped and bare tiles before and after the test are shown. The bare tile, shown in Figure 3, is perforated at the projectile velocity of $150 \mathrm{~m} / \mathrm{s}$. Considering the increase of the velocity up to $162 \mathrm{~m} / \mathrm{s}$, the wrapped tile is not perforated, as shown in Figure 3. Based on the experiments, the fracture conoid formation is reported in both cases whether the projectile perforated the tiles or not.

According to Table 1, the maximum value of the projectile velocity, at which the projectile did not perforate the bare tile, is $140 \pm 2 \mathrm{~m} / \mathrm{s}$, and the smallest velocity of projectile, in which perforation occurred, is $150 \pm 2 \mathrm{~m} / \mathrm{s}$. Thus, BLV of the bare tiles, which is the mean of these two values, is determined as $145 \pm 2 \mathrm{~m} / \mathrm{s}$. Similar to the bare tiles, BLV of the wrapped tiles is identified as $168 \pm 2 \mathrm{~m} / \mathrm{s}$. Therefore, it can be concluded that wrapping a ceramic tile by a light aluminum foil considerably enhances its BLV and energy absorption.

\section{Numerical study}

In this section, numerical simulation of the steel projectiles penetration in the ceramic tiles is carried out. Numerical simulations are performed in commercial finite element software, LS-DYNA.

\subsection{Material parameters identification}

Johnson-Cook model is used for simulation of plastic behavior of the projectile as well as the aluminum foil under dynamic load. In this model, flow stress, $\sigma$, is expressed as follows [38]:

$$
\sigma=\left(A+B\left(\bar{\varepsilon}^{p}\right)^{n}\right)\left(1+C \ln \dot{\varepsilon}^{*}\right)\left(1-T^{*^{m}}\right),
$$

where $\bar{\varepsilon}^{p}$ and $\dot{\varepsilon}^{*}$ are the equivalent plastic strain and the effective total strain rate, respectively. Dimensionless parameter, $T^{*}=\left(T-T_{r}\right) /\left(T_{m}-T_{r}\right)$, is homologues temperature in which $T$ is temperature, while $T_{r}$ and $T_{m}$ are room and melt temperatures, respectively. Also, $A, B, C, m$, and $n$ are material parameters. Moreover, this model consists of a damage part in which the strain at fracture is:

$$
\varepsilon^{f}=\left(D_{1}+D_{2} \exp \left(D_{3} \Sigma^{*}\right)\right)\left(1+D_{4} \ln \dot{\varepsilon}^{*}\right)\left(1+D_{5} T^{*}\right),
$$

where $\Sigma^{*}=\left(p / \sigma_{\text {eff }}\right)$ is the ratio of pressure divided by the effective stress; $D_{1}, D_{2}, D_{3}, D_{4}$, and $D_{5}$ are material parameters. For Al-1100, both the plastic and damage behaviors are considered. The material parameters are reported in Table 2 , where $\rho, E, \nu$, and $C_{p}$ are density, Young's modulus, Poisson ratio, and specific heat capacity, respectively. The material parameters for 4340 steel are also reported in Table 3 [39].

Johnson-Holmquist model is employed to simulate the behavior of ceramic tiles under dynamic load. This model is used for brittle materials which considers the strain rate effects and the damage evolution in 
Table 2. Johnson-Cook material parameters for Al-1100 [43].

\begin{tabular}{cccccccc}
\hline $\boldsymbol{\rho}\left(\mathrm{kg} / \mathbf{m}^{\mathbf{3}}\right)$ & $\boldsymbol{E}(\mathrm{GPa})$ & $\boldsymbol{\nu}(-)$ & $\boldsymbol{A}(\mathrm{MPa})$ & $\boldsymbol{B}(\mathrm{MPa})$ & $\boldsymbol{C}(-)$ & $\boldsymbol{m}(-)$ & $\boldsymbol{n}(-)$ \\
\hline 2700 & 65.76 & 0.3 & 148.36 & 345.51 & 0.001 & 0.859 & 0.183 \\
\hline $\boldsymbol{T}_{\boldsymbol{m}}(\mathbf{K})$ & $\boldsymbol{T}_{\boldsymbol{r}}(\mathbf{K})$ & $\boldsymbol{C}_{\boldsymbol{p}}(\mathbf{J} / \mathbf{k g ~ K})$ & $\boldsymbol{D}_{\mathbf{1}}(-)$ & $\boldsymbol{D}_{\mathbf{2}}(-)$ & $\boldsymbol{D}_{\mathbf{3}}(-)$ & $\boldsymbol{D}_{\mathbf{4}}(-)$ & $\boldsymbol{D}_{\mathbf{5}}(-)$ \\
\hline 893 & 293 & 920 & 0.071 & 1.248 & -1.142 & 0.147 & 0 \\
\hline
\end{tabular}

Table 3. Johnson-Cook material parameters for 4340 Steel [39].

\begin{tabular}{cccccccccc}
\hline $\boldsymbol{\rho}\left(\mathrm{kg} / \mathbf{m}^{\mathbf{3}}\right)$ & $\boldsymbol{E}(\mathrm{GPa})$ & $\boldsymbol{\nu}(-)$ & $\boldsymbol{A}(\mathbf{M P a})$ & $\boldsymbol{B}(\mathbf{M P a})$ & $\boldsymbol{C}(-)$ & $\boldsymbol{m}(-)$ & $\boldsymbol{n}(-)$ & $\boldsymbol{T}_{\boldsymbol{m}}(\mathbf{K})$ & $\boldsymbol{T}_{\boldsymbol{r}}(\mathbf{K})$ \\
\hline 7850 & 205 & 0.29 & 792.19 & 509.51 & 0.014 & 1.03 & 2.6 & 1700 & 293 \\
\hline
\end{tabular}

which the equivalent normalized stress, $\hat{\sigma}$, is expressed as $[38,40]$ :

$$
\hat{\sigma}=\hat{\sigma}_{i}-D\left(\hat{\sigma}_{i}-\hat{\sigma}_{f}\right)
$$

where $D$ is the accumulated damage due to an increase in plastic strain, and superscript "', indicates that the values are normalized with respect to Hugoniot Elastic Limit (HEL) value. Also, intact ceramic strength, $\hat{\sigma}_{i}$, is equal to $[38,40]$ :

$$
\hat{\sigma}_{i}=a(\hat{p}+\hat{t})^{N}(1+c \ln \dot{\varepsilon}),
$$

in which $\hat{t}$ and $\hat{p}$ are normalized tensile and pressure parts of equivalent stress, respectively. To represent the damage behavior, plastic strain at failure $\left(\varepsilon_{f}^{p}\right)$ and damaged material strength $\left(\hat{\sigma}_{f}\right)$ are defined as:

$$
\begin{aligned}
& \varepsilon_{f}^{p}=d_{1}(\hat{p}+\hat{t})^{d_{2}}, \\
& \hat{\sigma}_{f}=b(\hat{p})^{M}(1+c \ln \dot{\varepsilon}) \leq \text { SFMAX, }
\end{aligned}
$$

where $a, b, c, M, N, d_{1}$, and $d_{2}$ are material parameters. In addition, SFMAX is the maximum normalized fracture strength. Plastic strain at failure (FS) and maximum Tensile Strength (TS) are also required in the analysis. The model has also a hydrostatic part which relates the hydrostatic pressure $(p)$ to the density change in compression as [38,40]:

$$
p=k_{1} \mu+k_{2} \mu^{2}+k_{3} \mu^{3}
$$

where $\mu$ is the hydrostatic compression, and $k_{1}, k_{2}$, and $k_{3}$ are model parameters. Also, in tension, we have:

$$
p=k_{1} \mu \text {. }
$$

Johnson-Holmquist material parameters for $99.5 \%$ alumina used in this work are summarized in Table 4.

\subsection{Numerical simulation results}

Due to symmetry in the fracture conoid formation and the projectile deformation, an axisymmetric model is used to simulate projectile penetration in the ceramic tiles. 4-node axisymmetric elements with one integration point and hourglass control are used. The ceramic tiles model has 200 elements in thickness and 500 elements in radial direction. The projectile also contains 220 elements in height and 30 elements in radial direction. In addition, in the wrapped case, the aluminum foil consists of 382 elements. We highlight that the number of elements of the constructed model is refined enough to reach convergence and reveal crack growth in the ceramic tiles. The constructed numerical model is shown in Figure 2(c). We use AUTOMATICSURFACE-TO-SURFACE command in LS-DYNA to model contact between the projectile and the aluminum foil as well as the ceramic tile. Contact between the foil and the ceramic tile is then simulated by TIEDSURFACE-TO-SURFACE command [41]. At least 14 simulations are performed for which the minimum run time is 3 hours per one simulation. The results for various impact velocities, in both wrapped and bare tiles, are reported in Table 5. As observed, the results are in good agreement with the experimental data obtained in Section 2.2. In Figure 4, the fracture conoids obtained from experiments and simulations are compared, showing again very good agreement.

As an example, simulation of the projectile penetration in a bare ceramic tile at $150 \mathrm{~m} / \mathrm{s}$ is depicted in Figure 5(a) to (c) at different time instants. As shown in Figure $5(\mathrm{c})$, the projectile perforated the bare tile which is observed in the experiments. Also, progress of the crack growth and the fracture conoid formation is depicted at different instants after the projectile

Table 4. Johnson-Holmquist material parameters for $99.5 \%$ alumina tiles [44].

\begin{tabular}{cccccccc}
\hline $\boldsymbol{\rho}\left(\mathrm{kg} / \mathbf{m}^{\mathbf{3}}\right)$ & $\boldsymbol{G}(\mathrm{GPa})$ & $\boldsymbol{a}(-)$ & $\boldsymbol{b}(-)$ & $\boldsymbol{c}(-)$ & $\boldsymbol{M}(-)$ & $\boldsymbol{N}(-)$ & TS $(\mathrm{MPa})$ \\
\hline 3890 & 152 & 0.88 & 0.45 & 0.007 & 0.6 & .64 & 462 \\
\hline SFMAX (-) & HEL (GPa) & FS (-) & $\boldsymbol{d}_{\mathbf{1}}(-)$ & $\boldsymbol{d}_{\boldsymbol{2}}(-)$ & $\boldsymbol{k}_{\boldsymbol{1}}(\mathrm{GPa})$ & $\boldsymbol{k}_{\boldsymbol{2}}(\mathrm{GPa})$ & $\boldsymbol{k}_{\mathbf{3}}(\mathrm{GPa})$ \\
\hline 1 & 7 & 0.7 & 0.0125 & 0.7 & 231 & -160 & 2774 \\
\hline
\end{tabular}


Table 5. Simulation results of the projectile impact on the wrapped and bare tiles.

\begin{tabular}{ccccccc}
\hline \multicolumn{3}{c}{ Bare tile } & & & \multicolumn{3}{c}{ Wrapped tile } \\
\cline { 1 - 1 } \cline { 5 - 6 } $\begin{array}{c}\text { Simulation } \\
\text { no. }\end{array}$ & $\begin{array}{c}\text { Impact } \\
\text { velocity } \\
(\mathbf{m} / \mathbf{s})\end{array}$ & Perforation & & $\begin{array}{c}\text { Simulation } \\
\text { no. }\end{array}$ & $\begin{array}{c}\text { Impact } \\
\text { velocity } \\
(\mathbf{m} / \mathbf{s})\end{array}$ & Perforation \\
\hline 1 & 130 & No & & 8 & 140 & No \\
2 & 140 & No & & 9 & 150 & No \\
3 & 143 & Yes & & 10 & 160 & No \\
4 & 147 & Yes & & 11 & 164 & Yes \\
5 & 150 & Yes & & 12 & 168 & Yes \\
6 & 160 & Yes & 13 & 170 & Yes \\
7 & 170 & Yes & 14 & 180 & Yes \\
\hline
\end{tabular}

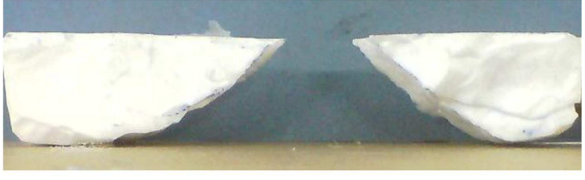

(a)

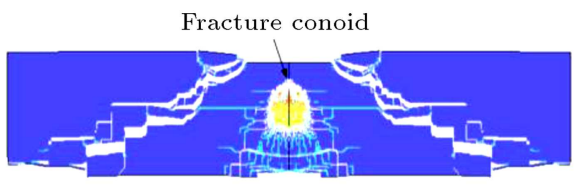

- Spall

(b)

Figure 4. (a) Experimental and (b) numerical results for fracture conoid in a bare tile at the velocity of $150 \mathrm{~m} / \mathrm{s}$.

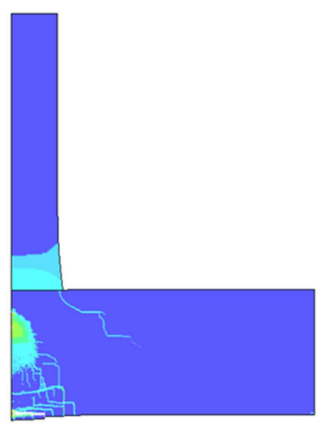

(a)

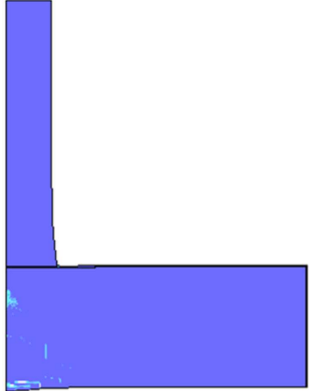

(d)

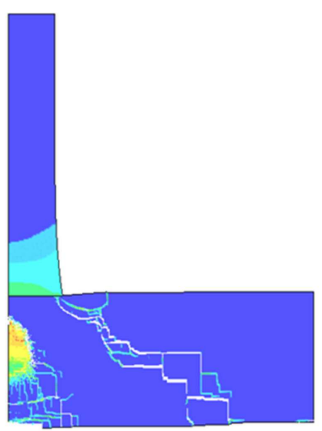

(b)

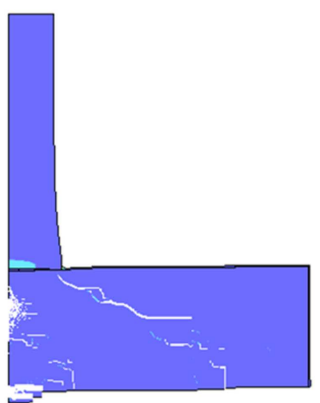

(e)

impact. Numerical simulation of the projectile penetration in a wrapped ceramic tile at $170 \mathrm{~m} / \mathrm{s}$ is shown in Figure 5(d) to (f). The projectile perforated the wrapped tile at this velocity which is in agreement with the experimental data. In both cases, the projectile deformation is small and its final shape is similar to that of Taylor impact test. This phenomenon is in agreement with the experimental results obtained from penetration tests shown in Figure 6.

\section{Results and discussion}

In this section, the experimental and numerical results are discussed, and the aluminum foil effect on BLV and

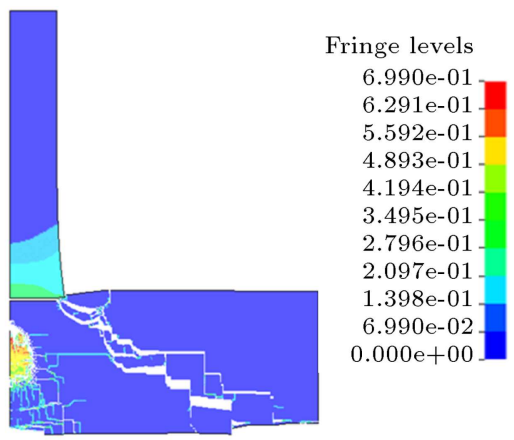

(c)

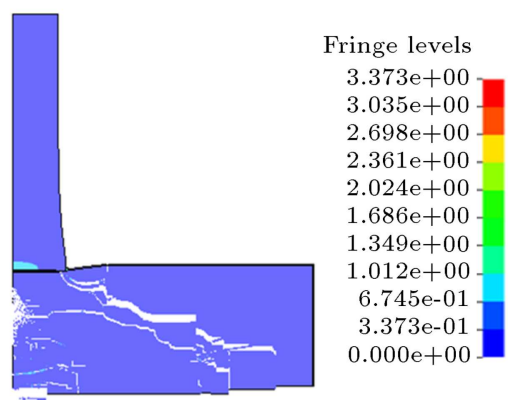

(f)

Figure 5. Penetration simulation of the bare tiles at $150 \mathrm{~m} / \mathrm{s}$ at (a) $6 \mu \mathrm{s}$, (b) $18 \mu \mathrm{s}$, and (c) $30 \mu \mathrm{s}$ after impact, and simulation of the projectile impact on the wrapped ceramic tiles at $170 \mathrm{~m} / \mathrm{s}$ at (d) $6 \mu \mathrm{s},(\mathrm{e}) 18 \mu \mathrm{s}$, and (f) $30 \mu \mathrm{s}$. 


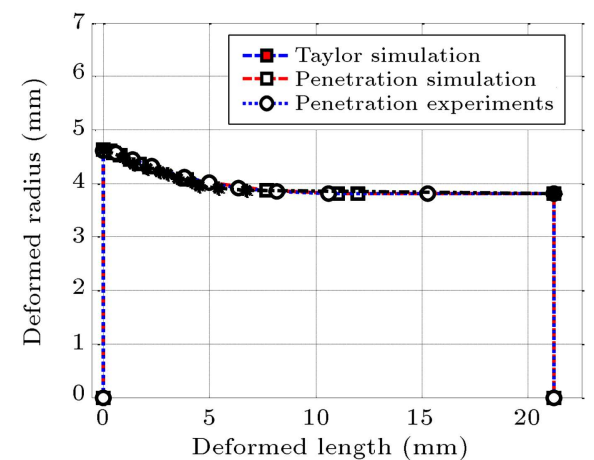

(a)

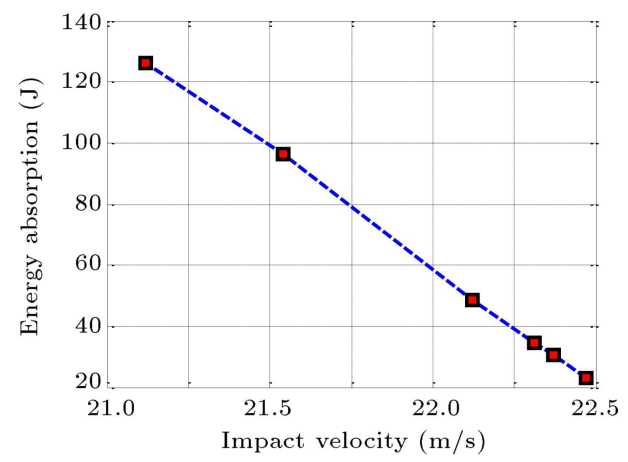

(b)

Figure 6. (a) Comparison of the scaled deformed projectiles in Taylor impact test simulation, penetration simulation and penetration experiment. (b) Energy absorption of a Taylor impact test specimen versus its final length after impact (simulation results).

energy absorption of the ceramic tiles for both cases is investigated. As mentioned in Section 2, BLV is assumed to be the average of the largest velocity in which the projectile does not perforate the tile and the smallest velocity in which the perforation occurs. Thus, based on the experimental results, BLV is obtained as $168 \pm 2$ and $145 \pm 2 \mathrm{~m} / \mathrm{s}$ for the wrapped and bare ceramic tiles, respectively. It is worthwhile to mention that due to the accuracy of the velocity measurement, the accuracy of the calculated BLV from the experimental results is also $\pm 2 \mathrm{~m} / \mathrm{s}$. Also, considering the numerical results, BLV of the wrapped and bare tiles is 162 and $141.5 \mathrm{~m} / \mathrm{s}$, respectively, which is in good agreement with the experimental data. Therefore, BLV of the wrapped tiles increases at least $19 \mathrm{~m} / \mathrm{s}$ with respect to the bare ones. The weights of foil, adhesive layer, and the bare ceramic tile are 0.7, 1.5, and $93.0 \mathrm{gr}$, respectively. Thus, it can be concluded that wrapping the ceramic tile by the aluminum foil results in $13 \%$ increase in its BLV with respect to the bare case, while its weight is increased by just $2.4 \%$.

To calculate energy absorption of the tiles, kinetic energy change of the projectile $(\Delta \mathrm{KE})$ is required which is:

$$
\Delta \mathrm{KE}=m_{p}\left(v_{i}^{2}-v_{r}^{2}\right) / 2,
$$

where $m_{p}, v_{i}$, and $v_{r}$ are mass, impact, and residual velocity of the projectile, respectively, in which the value of $v_{r}^{2}$ is negligible with respect to $v_{i}^{2}$. Kinetic energy change of the projectile is due to energy absorption of the ceramic tile and the projectile. Thus, we can obtain energy absorption of the ceramic tiles by calculating the kinetic energy change as well as absorbed energy of the projectile.

In order to calculate energy absorption of the projectile during plastic deformation, we first investigate the projectile deformation. Considering projectile profile from numerical simulation of the penetration test, numerical simulation of Taylor impact test, and experimental results obtained in this work as shown in Figure 6(a), it is assumed that the projectile deformation is similar to that of the Taylor impact. As depicted in Figure 6(a), deformation of the projectile in these cases is very similar. Taylor impact test is simulated in LS-DYNA and energy absorption of the projectile is plotted versus its final length, as shown in Figure 6(b). Subtracting energy absorption of the projectile from the change of its kinetic energy, energy absorption of the ceramic tiles is obtained. Using the experimental data from Table 1 and the numerical results from Figure 6(b), energy absorption of the projectile is calculated and reported in the same table as well.

The changes in the kinetic energy of the projectile as well as its energy absorption, and consequently, energy absorption of the tiles are calculated for the wrapped and bare tiles and depicted in Figure 7 (a) and (b) in terms of the impact velocity. As shown in Figure 7(a) and (b), increasing the impact velocity eventuates in an increase in energy absorption of the both wrapped and bare tiles. Energy absorption of the wrapped and the bare tiles is also compared in Figure 7(c). As shown in Figure 7(c), energy absorption of the wrapped tile is greater than the bare case at a particular impact velocity. The amount of increase in energy absorption of the wrapped tiles as well as the percentage of its increase with respect to the bare tiles are also shown in Figure $7(\mathrm{~d})$. As shown in Figure $7(\mathrm{~d})$, at least $11 \%$ increase in energy absorption is attained only by $2.4 \%$ increase in weight of the tiles. This value is increased as the projectile velocity increases which is $15 \%$ at $180 \mathrm{~m} / \mathrm{s}$.

To investigate the reason of increase in BLV and energy absorption of the wrapped tiles, we focus on the fracture conoid formation in both cases. Due to the good agreement between experiments and numerical simulations as discussed in Section 3.2, numerical results are employed to investigate the facture conoid formation in tiles. As shown in Figure 8(c) and (d), the fracture amount of $4^{\circ}$. Also, based on the experimental 


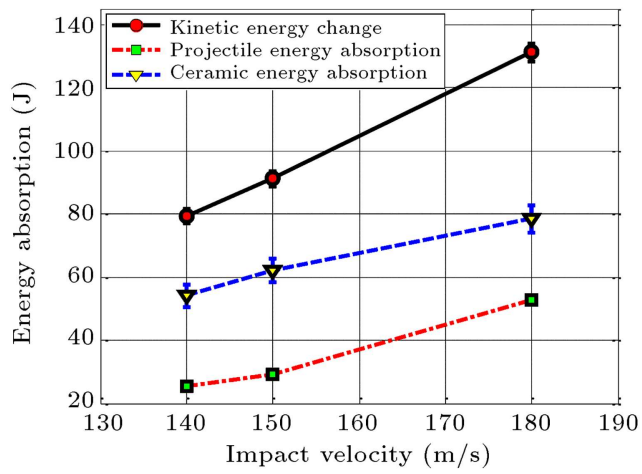

(a)

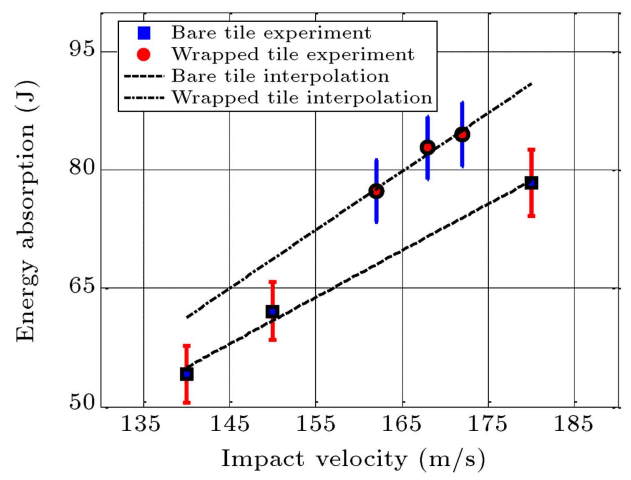

(c)

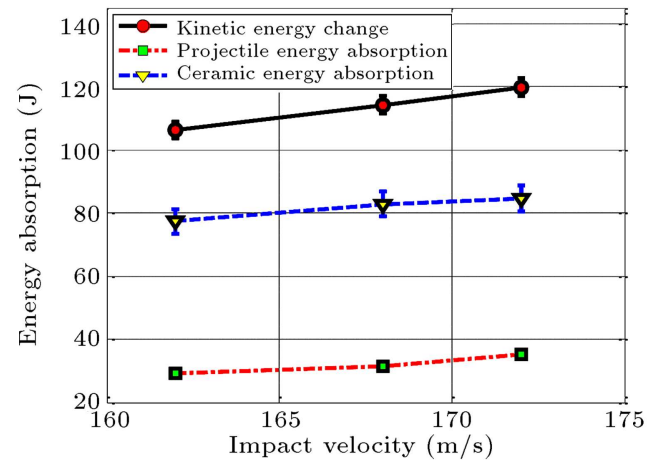

(b)

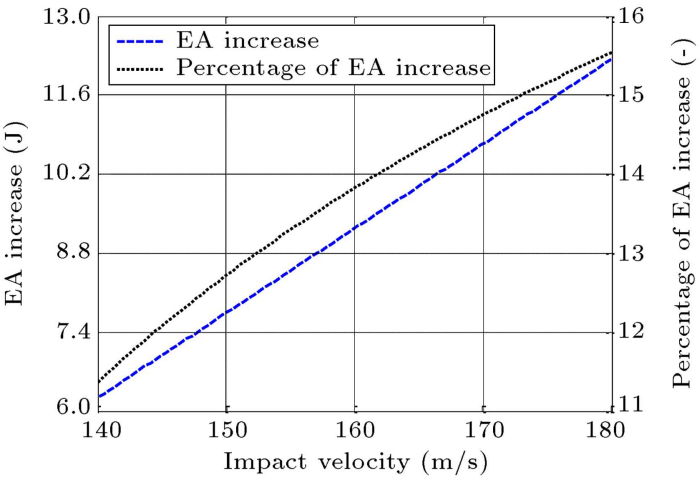

(d)

Figure 7. Kinetic Energy (KE) change, projectile and ceramic tile energy absorption for (a) bare and, (b) wrapped tiles. (c) Comparison of Energy Absorption (EA) in the wrapped and bare tiles. (d) Increase in energy absorption of the wrapped tiles with respect to the bare ones.

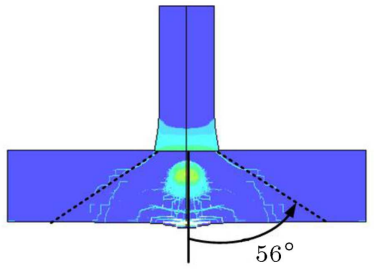

(a)

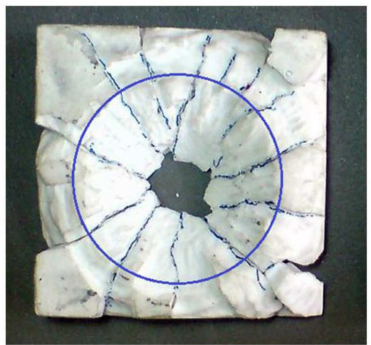

(c)

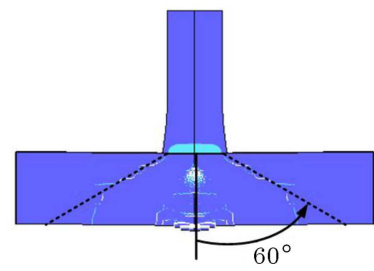

(b)

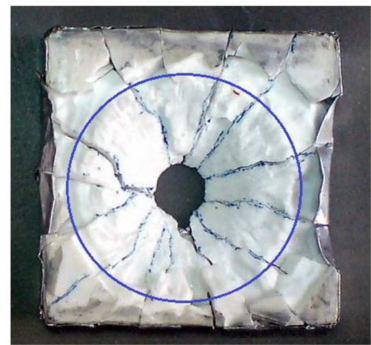

(d)
Figure 8. Numerical results of fracture conoid formation in (a) the bare and (b) the wrapped tiles. Experimental results for fracture conoid formation in (c) the bare and (d) the wrapped tiles.

results, as depicted in Figure 8, the diameter of the fracture conoid is greater in the wrapped cases which qualitatively validates the numerical results. Based on the above results, we conclude that wrapping the ceramic tiles by an aluminum foil enhances energy ab- sorption by two mechanisms. Firstly, the components of the fractured ceramic tiles are kept together by the foil during projectile penetration, resulting in more energy absorption. Secondly, as depicted in Figure 8, the fracture conoid angle is increased in the wrapped tiles which enhances the crack length and postpones the crack arrival to the back face of the tile, and as a result, an increase in energy absorption as well as BLV is observed $[34,42]$.

\section{Summary and conclusions}

In this paper, the effect of aluminum foil wrapping on Ballistic Limit Velocity (BLV) and energy absorption of the alumina ceramic tiles was studied. The aluminum foil was added to the impact face of the ceramic tile while its back face was free. In this regard, penetration tests were performed for both the wrapped and the bare tiles. Numerical simulation of the penetration in the ceramic tiles was also carried out, which was in good agreement with the experimental results. Crack growth and fracture conoid formation were also captured by numerical simulations.

Based on the experimental results, BLV of the wrapped and the bare tiles was determined as $168 \pm 2$ and $145 \pm 2 \mathrm{~m} / \mathrm{s}$, respectively. Also, from the numerical results, BLV was calculated as 162 and $141.5 \mathrm{~m} / \mathrm{s}$ 
for the wrapped and bare tiles, respectively, which were in good agreement with experiments. Thus, it can be concluded that BLV of the wrapped ceramic tile increases at least $13 \%$ just by $2.4 \%$ increase in the tile weight due to the aluminum foil wrapping. Based on the experimental results, energy absorption of the ceramic tiles was then calculated. The results revealed that in the velocity range of $140-180 \mathrm{~m} / \mathrm{s}$, which is in the vicinity of tiles BLV, energy absorption of the wrapped tiles is at least $11 \%$ more than that of the bare tiles. This value was reached $15 \%$ at $180 \mathrm{~m} / \mathrm{s}$.

Finally, the aluminum foil role was investigated based on the experimental and numerical results. Aluminum foil keeps the fractured ceramic components with each other for extra time which enhances energy absorption of the wrapped tiles. Also, fracture conoid angle of the wrapped tiles is greater than that of the bare ones resulting in larger crack length, postponing the crack propagation to the back face, and enhancing BLV of the wrapped tiles.

\section{Acknowledgement}

This research has been partially supported by the Impact Mechanics and Penetration Laboratory (IMPLab) of Mechanical Engineering Department, Sharif University of Technology which is gratefully acknowledged.

\section{References}

1. Sarva, S., Nemat-Nasser, S., McGee, J., et al. "The effect of thin membrane restraint on the ballistic performance of armor grade ceramic tiles", International Journal of Impact Engineering, 34(2), pp. 277-302 (2007).

2. Simha, C.H.M., Bless, S.J. and Bedford, A. "Computational modeling of the penetration response of a high-purity ceramic", International Journal of Impact Engineering, 27(1), pp. 65-86 (2002).

3. Hazell, P.J., Fellows, N.A. and Hetherington, J.G. "A note on the behind armour effects from perforated alumina/aluminium targets", International Journal of Impact Engineering, 21(7), pp. 589-595 (1998).

4. Liu, W., Chen, Z., Cheng, X., et al. "Design and ballistic penetration of the ceramic composite armor", Composites Part B: Engineering, 84, pp. 33-40 (2016).

5. Huang, C.-Y. and Chen, Y.-L. "Design and impact resistant analysis of functionally graded $\mathrm{Al}_{2} \mathrm{O}_{3}-\mathrm{ZrO}_{2}$ ceramic composite", Materials \& Design, 91, pp. 294305 (2016).

6. Florence, A., Interaction of Projectiles and Composite Armours Part II, Stanford Research Institute, Menlo Park, California, USA, California (1969).
7. Reijer, P.C., Impact on Ceramic Faced Armours, Delft University of Technology, Delft (1991).

8. Zaera, R. and Sánchez Gálvez, V. "Analytical modelling of normal and oblique ballistic impact on ceramic/metal lightweight armours", International Journal of Impact Engineering, 21(3), pp. 133-148 (1998).

9. Übeyli, M., YildIrIm, R.O. and Ögel, B. "On the comparison of the ballistic performance of steel and laminated composite armors", Materials \& Design, 28(4), pp. 1257-1262 (2007).

10. Ben-Dor, G., Dubinsky, A. and Elperin, T. "Improved Florence model and optimization of two-component armor against single impact or two impacts", Composite Structures, 88(1), pp. 158-165 (2009).

11. Zaera, R., Sánchez-Sáez, S., Pérez-Castellanos, J.L., et al. "Modelling of the adhesive layer in mixed ceramic/metal armours subjected to impact", Composites Part A: Applied Science and Manufacturing, 31(8), pp. 823-833 (2000).

12. López-Puente, J., Arias, A., Zaera. R., et al. "The effect of the thickness of the adhesive layer on the ballistic limit of ceramic/metal armours. An experimental and numerical study", International Journal of Impact Engineering, 32(1-4), pp. 321-336 (2005).

13. Öberg, E., Dean, J. and Clyne, T. "Effect of inter-layer toughness in ballistic protection systems on absorption of projectile energy", International Journal of Impact Engineering, 76, pp. 75-82 (2015).

14. Hetherington, J.G. "The optimization of two component composite armours", International Journal of Impact Engineering, 12(3), pp. 409-414 (1992).

15. Lee, M. and Yoo, Y.H. "Analysis of ceramic/metal armour systems", International Journal of Impact Engineering, 25(9), pp. 819-829 (2001).

16. Lee, M. "Hypervelocity impact into oblique ceramic/metal composite systems", International Journal of Impact Engineering, 29(1-10), pp. 417-424 (2003).

17. Holland, C.C., Gamble, E.A., Zok, F.W., et al. "Effect of design on the performance of steel-alumina bilayers and trilayers subject to ballistic impact", Mechanics of Materials, pp. 241-251 (2015).

18. Liu, W., Chen, Z., Chen, Z., et al. "Influence of different back laminate layers on ballistic performance of ceramic composite armor", Materials \& Design, 87, pp. $421-427$ (2015).

19. Madhu, V., Ramanjaneyulu, K., Balakrishna Bhat, T., et al. "An experimental study of penetration resistance of ceramic armour subjected to projectile impact", International Journal of Impact Engineering, 32(1-4), pp. 337-350 (2005).

20. Hazell, P.J., Roberson, C.J. and Moutinho, M. "The design of mosaic armour: The influence of tile size on 
ballistic performance", Materials \& Design, 29(8), pp. 1497-1503 (2008).

21. Übeyli, M., Deniz, H., Demir, T., et al. "Ballistic impact performance of an armor material consisting of alumina and dual phase steel layers", Materials \& Design, 32(3), pp. 1565-1570 (2011).

22. Rozenberg, Z. and Yeshurun, Y. "The relation between ballastic efficiency and compressive strength of ceramic tiles", International Journal of Impact Engineering, 7(3), pp. 357-362 (1988).

23. Anderson, J.C.E. and Morris, B.L. "The ballistic performance of confined $\mathrm{Al}_{2} \mathrm{O}_{3}$ ceramic tiles", International Journal of Impact Engineering, 12(2), pp. 167187 (1992)

24. Anderson Jr, C.E., Behner, T., Orphal, D.L., et al. "Time-resolved penetration into pre-damaged hotpressed silicon carbide", International Journal of Impact Engineering, 35(8), pp. 661-673 (2008).

25. Woodward, R.L., Gooch, G.W.A., O'Donnell, R.G., et al. "A study of fragmentation in the ballistic impact of ceramics", International Journal of Impact Engineering, 15(5), pp. 605-618 (1994).

26. Quan, X., Clegg, R.A., Cowler, M.S., et al. "Numerical simulation of long rods impacting silicon carbide targets using JH-1 model", International Journal of Impact Engineering, 33(1-12), pp. 634-644 (2006).

27. Zhang, X.F. and Li, Y.C. "On the comparison of the ballistic performance of $10 \%$ zirconia toughened alumina and $95 \%$ alumina ceramic target", Materials \& Design, 31(4), pp. 1945-1952 (2010).

28. Bresciani, L., Manes, A., Romano, T., et al. "Numerical modelling to reproduce fragmentation of a tungsten heavy alloy projectile impacting a ceramic tile: Adaptive solid mesh to the SPH technique and the cohesive law", International Journal of Impact Engineering, 87, pp. 3-13 (2016).

29. Anderson Jr, C.E. and Morris, B.L. "The ballistic performance of confined $\mathrm{Al}_{2} \mathrm{O}_{3}$ ceramic tiles", International Journal of Impact Engineering, 12(2), pp. 167187 (1992).

30. Holmquist, T.J. and Johnson, G.R. "Modeling prestressed ceramic and its effect on ballistic performance", International Journal of Impact Engineering, 31(2), pp. 113-127 (2005).

31. Chocron, I.S., Anderson, J.C.E., Behner, T., et al. "Lateral confinement effects in long-rod penetration of ceramics at hypervelocity", International Journal of Impact Engineering, 33(1-12), pp. 169-179 (2006).

32. Lynch, N.J., Bless, S.J., Cullis, I.G., et al. "The influence of confinement on the penetration of ceramic targets by KE projectiles at 1.8 and $2.6 \mathrm{~km} / \mathrm{s}$, International Journal of Impact Engineering, 33(1-12), pp. 390-401 (2006).
33. Sherman, D. and Ben-Shushan, T. "Quasi-static impact damage in confined ceramic tiles", International Journal of Impact Engineering, 21(4), pp. 245-265 (1998).

34. Sherman, D. "Impact failure mechanisms in alumina tiles on finite thickness support and the effect of confinement", International Journal of Impact Engineering, 24(3), pp. 313-328 (2000).

35. Zuoguang, Z., Mingchao, W., Shuncheng, S., et al. "Influence of panel/back thickness on impact damage behavior of alumina/aluminum armors", Journal of the European Ceramic Society, 30(4), pp. 875-887 (2010).

36. Wang, Q., Chen, Z. and Chen, Z. "Design and characteristics of hybrid composite armor subjected to projectile impact", Materials \& Design, 46(0), pp. 634639 (2013).

37. Reddy, P.R.S., Madhu, V., Ramanjaneyulu, K., et al. "Influence of polymer restraint on ballistic performance of alumina ceramic tiles", Defence Science Journal -New Delhi-, 58(2), pp. 264-274 (2008).

38. LS-DYNA keyword user's manual, Livermore Software Technology Corporation (2007).

39. Zukas, J., High Velocity Impact Dynamics, First Ed., Wiley-Interscience (1990).

40. Johnson, G.R. and Holmquist, T.J. "An improved computational constitutive model for brittle materials High-pressure science and technology", AIP Conference Proceedings, 309, pp. 981-984 (1993).

41. Fawaz, Z., Zheng, W. and Behdinan, K. "Numerical simulation of normal and oblique ballistic impact on ceramic composite armours", Composite Structures, 63(3-4), pp. 387-395 (2004).

42. Wilkins, M.L. "Mechanics of penetration and perforation", International Journal of Engineering Science, 16(11), pp. 793-807 (1978).

43. Gupta, N.K., Iqbal, M.A. and Sekhon, G.S. "Effect of projectile nose shape, impact velocity and target thickness on deformation behavior of aluminum plates", International Journal of Solids and Structures, 44(10), pp. 3411-3439 (2007).

44. Tasdemirci, A. and Hall, I.W. "Numerical and experimental studies of damage generation in multi-layer composite materials at high strain rates", International Journal of Impact Engineering, 34(2), pp. 189204 (2007).

\section{Biographies}

Hashem Mazaheri received his BS, MS, and PhD degrees in Mechanical Engineering from Sharif University of Technology, Tehran, Iran, in 2007, 2010, and 2015, respectively. He is now an Assistant Professor in Mechanical Engineering Department, Bu-Ali Sina 
University, Hamedan, Iran. His research interests include solid mechanics, computational mechanics, nonlinear finite element method, constitutive modeling of materials, especially smart hydrogels and design problems.

Reza Naghdabadi received his $\mathrm{PhD}$ degree in Mechanical Engineering from University of Waterloo, Canada in 1993. He is now a Professor in the Department of Mechanical Engineering at Sharif University of Technology, Iran. His research interests include solid mechanics, nano-mechanics, and computational mechanics.

Jamal Arghavani is currently an Assistant Professor at Mechanical Engineering Department at SUT. His long-term research interest is constitutive modeling (materials behavior modeling) under different loading conditions. In recent years, he has specially focused on constitutive modeling of shape memory alloys under multi-axial non-proportional thermo-mechanical loading. 